UCRL-ID-125434

\title{
Comparing a 2D Fluid Model of the DC Planar Magnetron Cathode to Experiments
}

\author{
Manuel Garcia
}

May 15, 1996

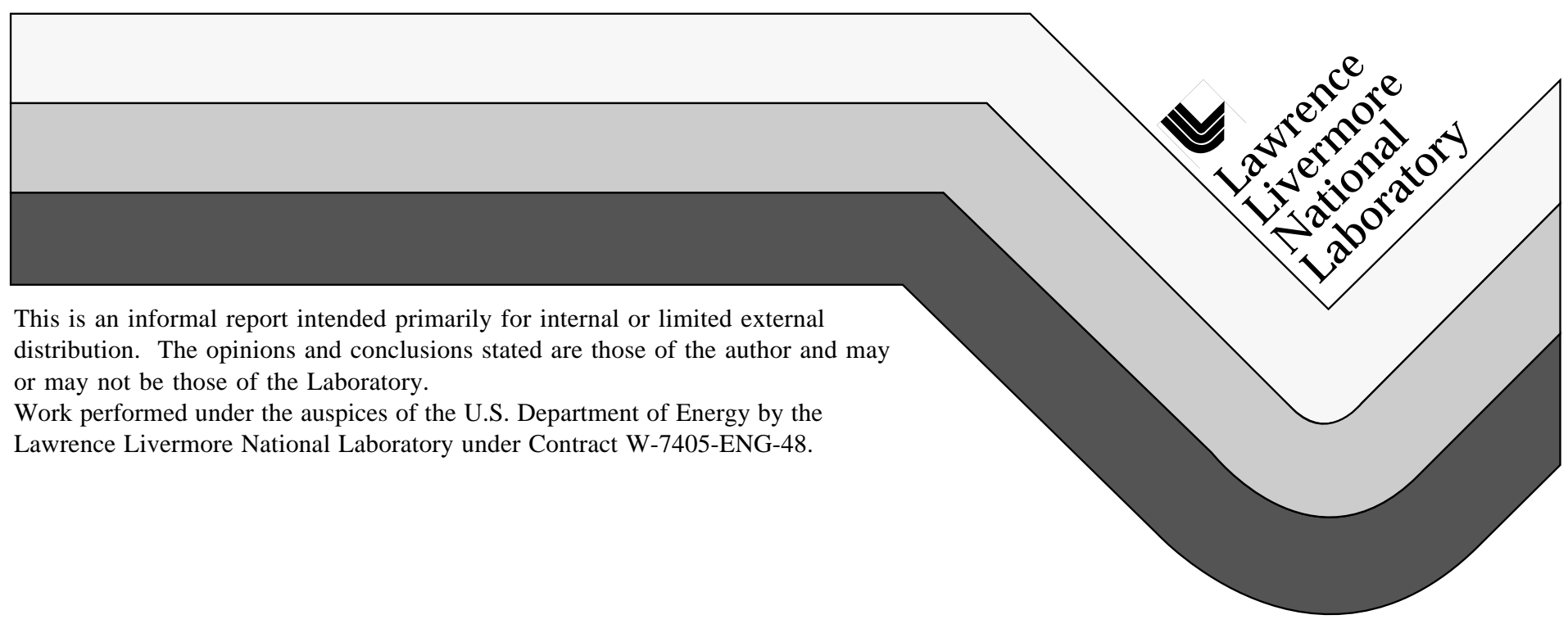




\section{DISCLAIMER}

This document was prepared as an account of work sponsored by an agency of the United States Government. Neither the United States Government nor the University of California nor any of their employees, makes any warranty, express or implied, or assumes any legal liability or responsibility for the accuracy, completeness, or usefulness of any information, apparatus, product, or process disclosed, or represents that its use would not infringe privately owned rights. Reference herein to any specific commercial product, process, or service by trade name, trademark, manufacturer, or otherwise, does not necessarily constitute or imply its endorsement, recommendation, or favoring by the United States Government or the University of California. The views and opinions of authors expressed herein do not necessarily state or reflect those of the United States Government or the University of California, and shall not be used for advertising or product endorsement purposes.

This report has been reproduced directly from the best available copy.

Available to DOE and DOE contractors from the Office of Scientific and Technical Information

P.O. Box 62, Oak Ridge, TN 37831

Prices available from (615) 576-8401, FTS 626-8401

Available to the public from the

National Technical Information Service

U.S. Department of Commerce 5285 Port Royal Rd.,

Springfield, VA 22161 


\title{
Comparing a 2D Fluid Model of the DC Planar Magnetron Cathode to Experiments
}

\author{
Manuel Garcia \\ May 15, 1996 \\ Lawrence Livermore National Laboratory, L-490, PO Box 808, Livermore CA 94550 \\ garcia22@1lnl.gov, (510) 422-6017, FAX: (510) 422-7748
}

Planar magnetron cathodes have arching magnetic field lines which concentrate plasma density near the electrode surface. This enhances the ion bombardment of the surface and the yield of sputtered atoms. Magnetron cathodes are used in the Plasma Electrode Pockels Cell (PEPC) devices of the Laser Program because they provide for significantly higher conduction than do glow discharges. An essential feature of magnetron cathodes is that the vector product of the perpendicular electric field, $\mathrm{E}_{\mathrm{y}}$, with the parallel component of the magnetic field, $\mathrm{B}_{\mathrm{x}}$, forms a closed track with a circulating current along the cathode surface. An analytical, 2D, two component, quasineutral, continuum model yields formulas for the plasma density: $\mathrm{n}(\mathrm{x}, \mathrm{y})$, the total and component current densities: $\mathbf{j}(\mathrm{x}, \mathrm{y}), \mathbf{j}_{\mathbf{e}}(\mathrm{x}, \mathrm{y}), \mathbf{j}_{+}(\mathrm{x}, \mathrm{y})$, the electric field: $\mathrm{E}_{\mathrm{y}}(\mathrm{y})$, and the positive electrical potential, $\phi_{\infty}$, between the cathode surface and a distant, uniform plasma. For a specific gas the free parameters are electron temperature, $T_{e}$, gas number density, $\mathrm{N}$, and total current, $\mathrm{I}_{0}$. The magnetic field $\mathbf{B}(\mathrm{x}, \mathrm{y})$ is assumed known. This model includes the convective terms $\left(\mathbf{v} \cdot \nabla \mathbf{v} / v_{\mathrm{e} N} \neq 0\right)$, and an explicit dependence on the collision frequency with gas molecules $\left(v_{\mathrm{eN}}, v_{+\mathrm{N}}\right)$. Typical parameters are: helium pressure of 1 to 100 milli-torr, $B$ at the cathode surface of 200 to 2000 gauss, voltage from 200 to 800 volts, and plasma density decreasing from one to three orders of magnitude within 3 to $10 \mathrm{~cm}$ from the cathode surface. The model is applied to the interpretation of experimental data from the PEPC device, as well as a small vacuum facility for testing magnetron cathodes. This comparison shows that $\mathrm{T}_{\mathrm{e}}$ for a magnetron cathode $(3 \rightarrow 8 \mathrm{eV})$ adjusts to ensure 
that $\alpha_{0} \tau \approx 2.5$ in helium, where $\alpha_{0}$ is the ionization rate $\left(10^{4} \rightarrow 10^{5} \mathrm{~s}^{-1}\right)$, and $\tau$ is the electron transit time between the cathode and the distant unmagnetized plasma (10 -> $100 \mu \mathrm{s})$. The $\alpha_{0} \tau$ through the cathode fall of a helium glow discharge is about 2.5, though this occurs at much higher voltage. Finally, the model has been applied to generate cross sectional views of a PEPC magnetron cathode track. These views illustrate why high current pulses applied to low current DC magnetron discharges are channeled to the outer edges of the track. All calculations and plots (including the synthesis of $\mathbf{B}(\mathrm{x}, \mathrm{y})$ ) are done in a single program with Mathcad3.1 on a Macintosh IIfx or a Macintosh IIsi computer.

\section{Introduction}

This report is a collection of illustrations utilized to amplify the description given in the abstract above, and originally presented as a seminar. The 2D fluid model referred to is fully described in UCRLID-122494 (available online). ${ }^{1}$ The present report will concentrate on these points: 1) the proper electron temperature to select in applying the model is that which produces $\alpha_{0} \tau \approx 2.5$ (helium discharge), and 2) the model is useful in visualizing the distribution of plasma and current flow in a discharge.

\section{Experimental Environment}

Figure $\mathbf{1}$ is a schematic of the PEPC device. Planar plasmas are created on either side of a sheet of KDP crystal, and used as transparent electrodes to impose a pulsed electric field through the sheet. KDP is an electro-optic material, and the plane of polarization of an incident laser beam is rotated under the action of this field. This device is an elaborate shutter. Magnetron cathodes have been used in PEPC devices because they provide for more plasma, and a higher conductivity "plasma electrode," than is the case with glow discharges. A typical magnetron cathode has two closed parallel tracks of magnets with different orientation: for example the outer track may have the north pole facing up, and the inner track with south pole up. This arrangement produces a closed circuit of transverse magnetic field along the cathode surface, and is shown in Figure 1 as a gray racetrack. Plasma density is concentrated in this 
track, and drifts along the closed path under the action of an $\mathbf{E} \times \mathbf{B}$ force.

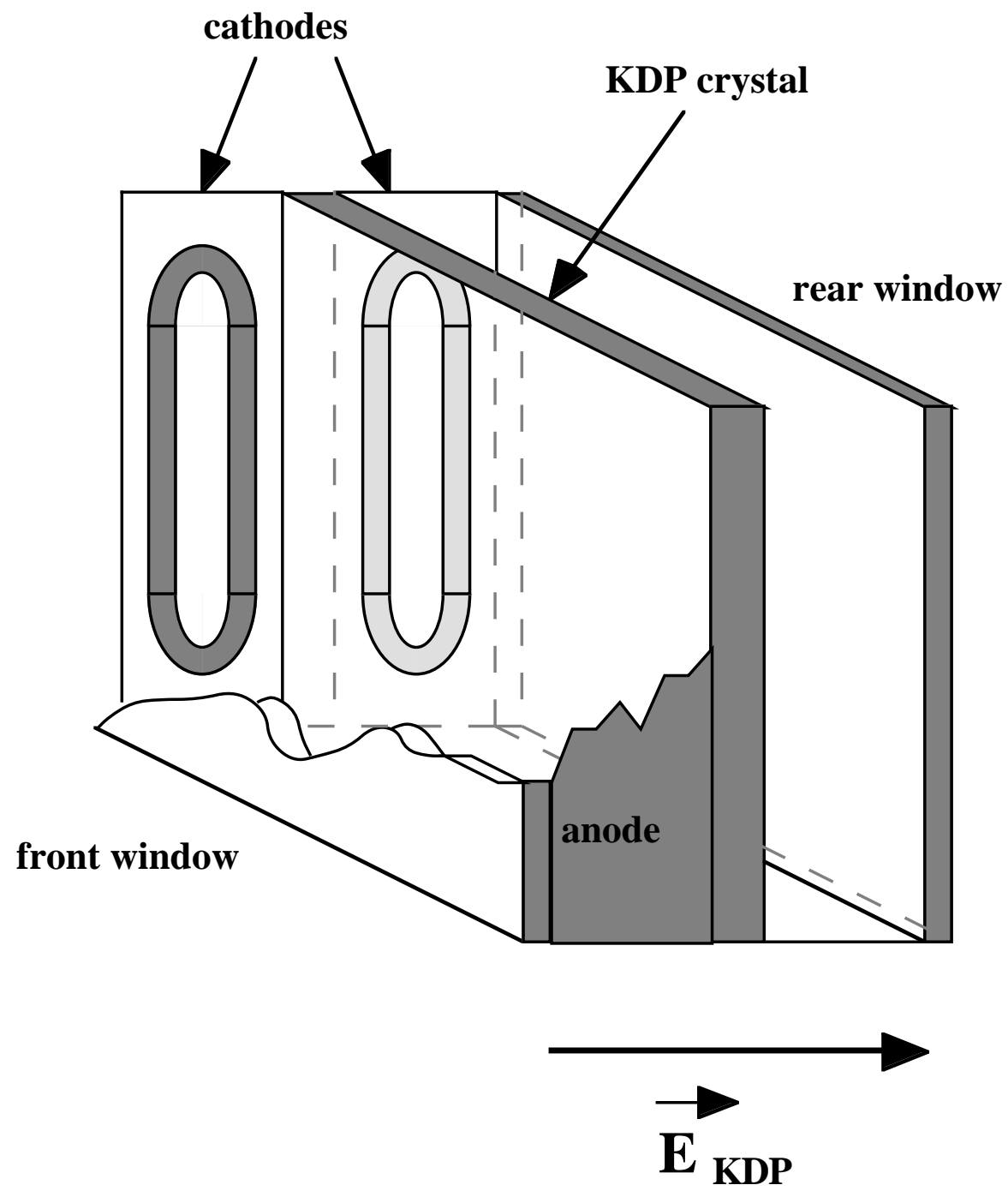

Figure 1: PEPC, for rotating laser beam plane of polarization

The dual magnet rail (on either side of the track) magnetron cathode just described has $0^{\circ}$ of tilt for its magnets with respect to the cathode perpendicular. Figure 2 shows a $28 \mathrm{~cm}$ square track in action. This cathode was one of many tested in a small vacuum facility where DC helium discharges were struck. 


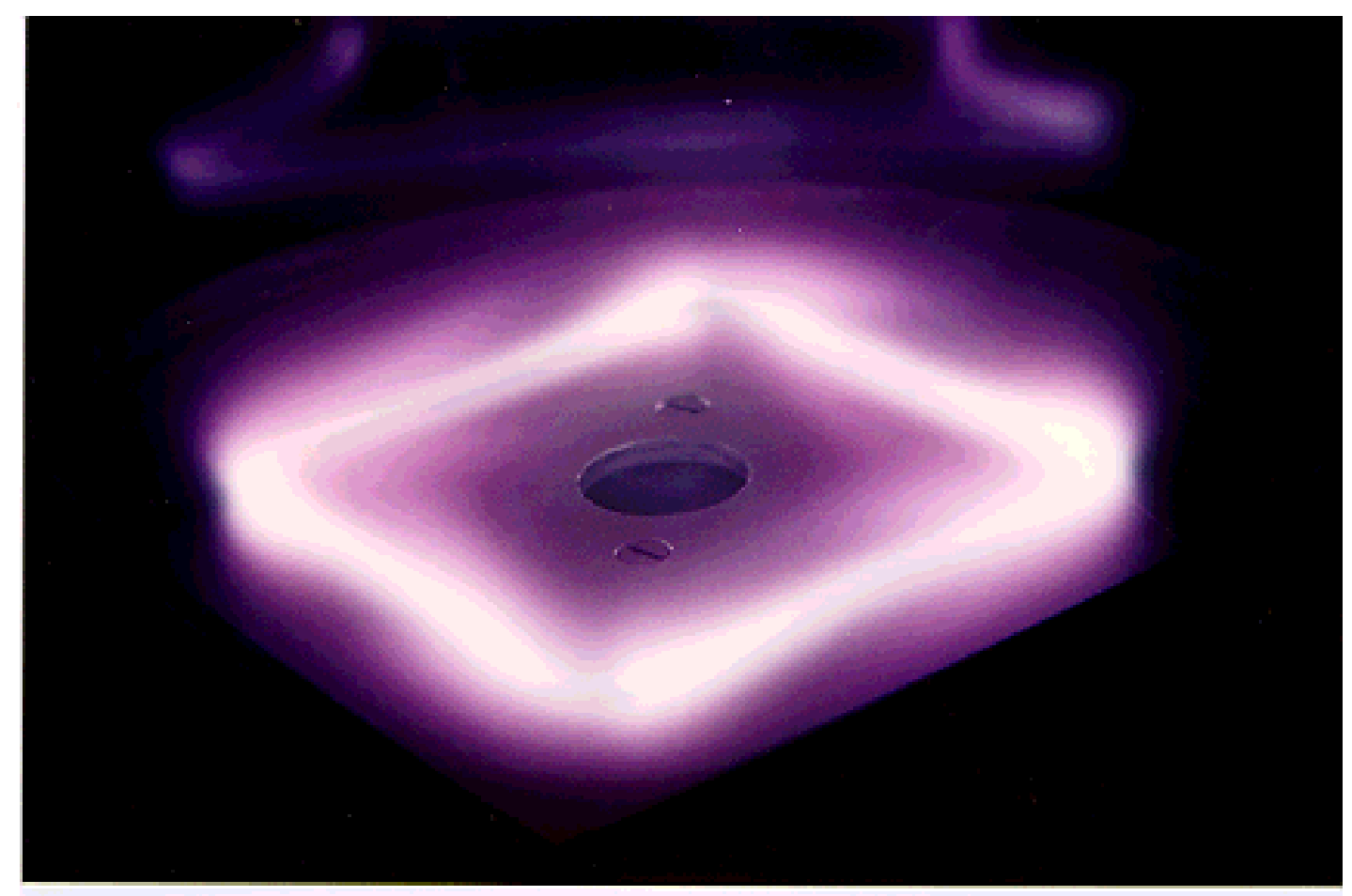

Figure 2: $0^{\circ}$ Square Magnetron Cathode @ 28 cm

Arrangements tested included those with magnet orientation tilted inward, outward, at $90^{\circ}$ and with a trench between pole faces along the track, and a single rail oriented at $90^{\circ}$ where the plasma ring rested above it. The arrangement that ultimately produced the lowest DC voltage for the current drawn was a "fin" above the cathode plate with an embedded single line of magnets at $90^{\circ}$. A plasma ring, or halo, circled the fin. Hollow cathodes (note the $2 \mathrm{~cm}$ diameter hole in Figure 2), and traditional glow discharges were also tested.

\section{Ionization Parameter $\alpha_{0} \tau$}

The electron temperature is assumed known in the model of the magnetron cathode fall region ${ }^{1}$. In reality the electron temperature adjusts to ensure that enough ionization occurs in the cathode fall to both maintain global current continuity, and to compensate for charge losses. For the helium discharges investigated this means that about 2.5 ionizations occur per charge transported between the cathode and the exterior plasma (positive column). This ratio was found to be the same in both glow and magnetron cathode discharges. 
The cathode fall voltage that results in any given helium discharge is simply that needed to produce $\alpha_{0} \tau \approx 2.5$, where $\alpha_{0}$ is the ionization coefficient, and $\tau$ is the transit time of electron fluid from the cathode surface through the cathode fall. For a magnetron cathode the "fall" extends to a point where plasma is unmagnetized, that is to say where the electron cyclotron frequency is less than the electron-neutral collision frequency. In a glow discharge a high cathode fall voltage and electric field are required in order to have electrons produce enough ionization during their rapid and brief transit. Lower voltage occurs in a magnetron cathode because the transverse magnetic field ensures a more leisurely drift of electrons from the cathode, and thus more time for lower energy electrons to produce the required ionization before they reach the positive column.

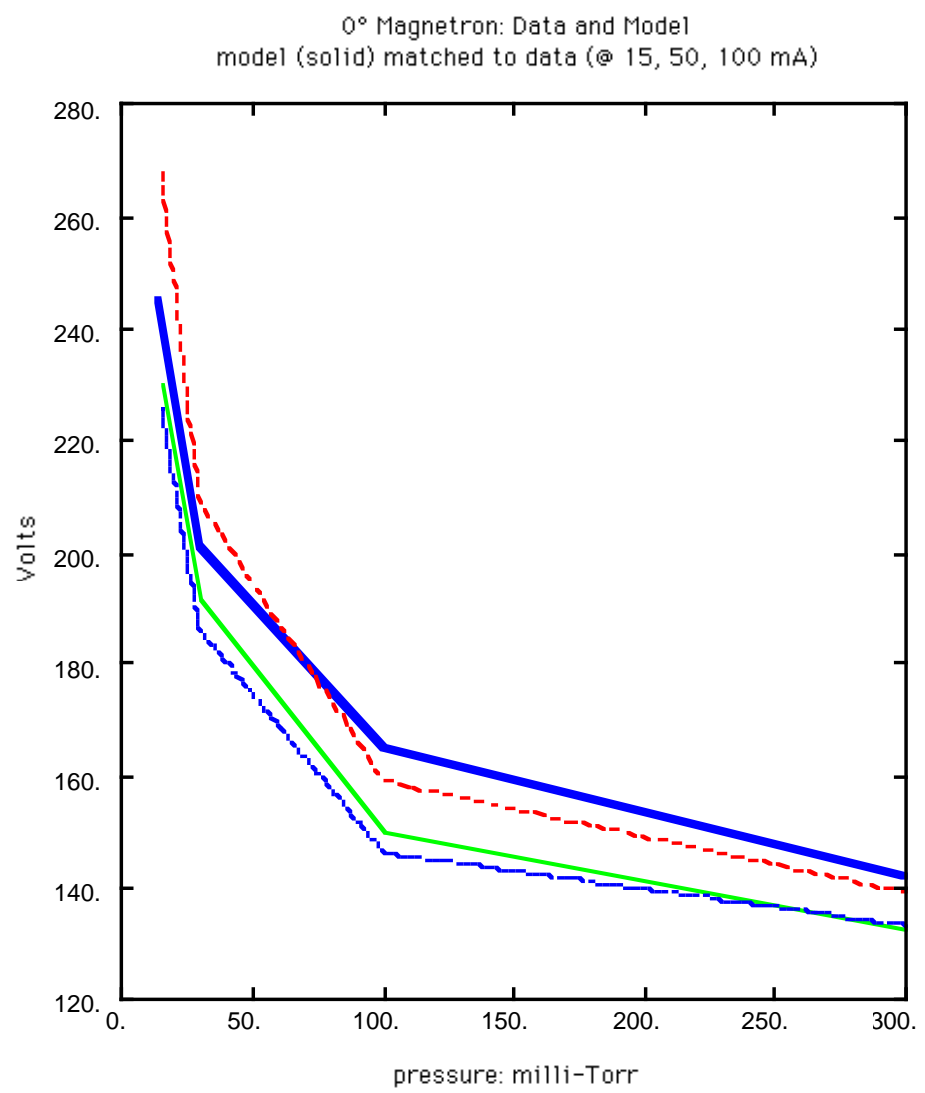

Figure 3: Model matched to experiment

In comparing the model with experiments $\mathrm{T}_{\mathrm{e}}$ is taken as that value which produces $\alpha_{0} \tau \approx 2.5$ for the given $\mathbf{B}(\mathrm{x}, \mathrm{y})$, gas density, and dimensional parameters. Figure $\mathbf{3}$ shows a comparison of voltagepressure curves for the square, $0^{\circ}$ magnetron cathode of Figure 2. Actual data points are at $\mathrm{p}=15,30,100$, and 300 milli-torr. Each data curve is at a constant current $(15,50$, and $100 \mathrm{~mA}$ : thin lines, 
bottom up). A model curve that follows the experimental trend is shown as a bold solid line.

The $\alpha_{0} \tau$ values that result from the model at each pressure by this comparison are show as the bold solid line in Figure 4. Also shown in Figure 4 is a similar result (dashed line) for a magnetron cathode with magnets tilted at $90^{\circ}$ to the cathode surface (a single track). Note that $\alpha_{0} \tau \approx 2.5$.

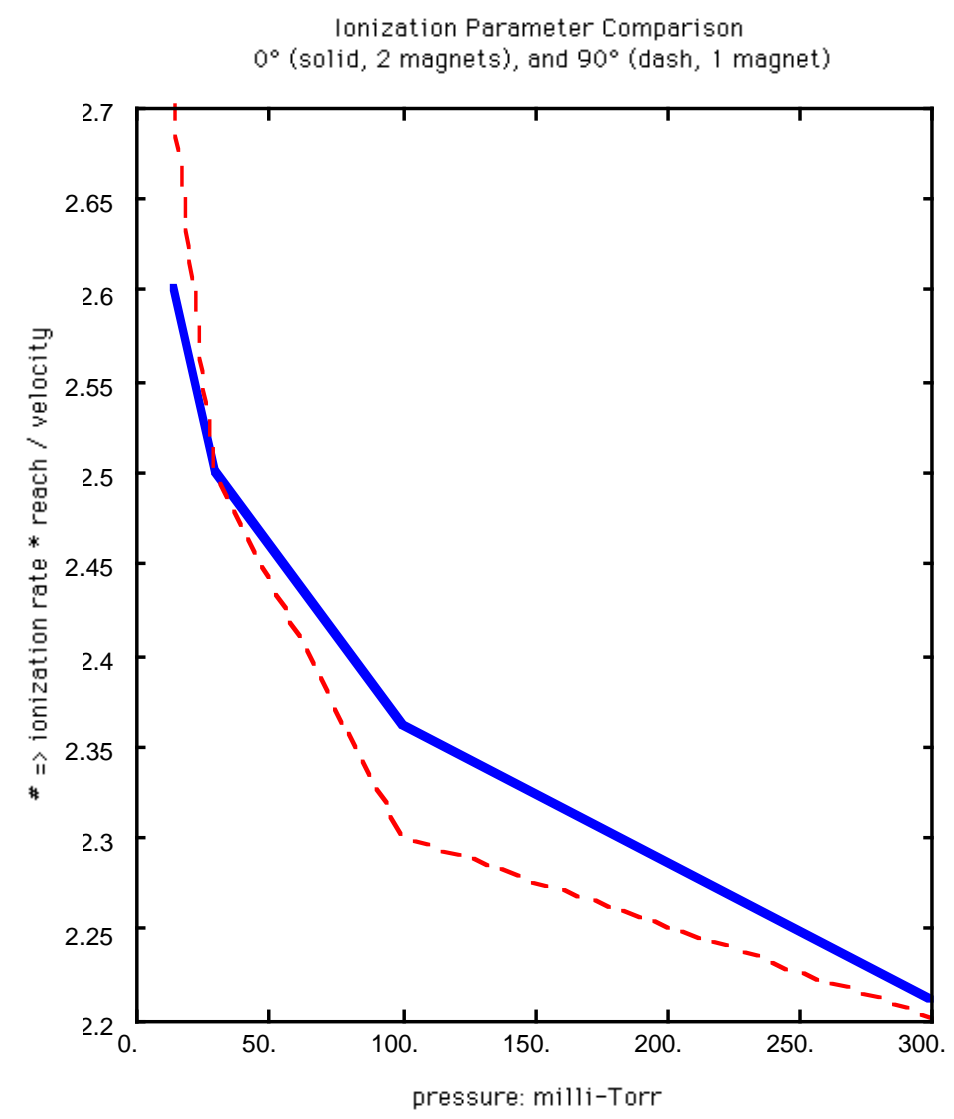

Figure 4: Ionization parameter to match experiments

For the examples of Figures 3 and $4, \mathrm{~T}_{\mathrm{e}}$ hovers near $7 \mathrm{eV}$; this sets $\alpha_{0}$. For the $0^{\circ}$ magnetron the model now provides an estimate of the electron fluid transit time, $\tau$, and the extent of the cathode fall, $\mathrm{y}_{0}$. Figure 5 shows these results (time is solid, distance is dashed). 


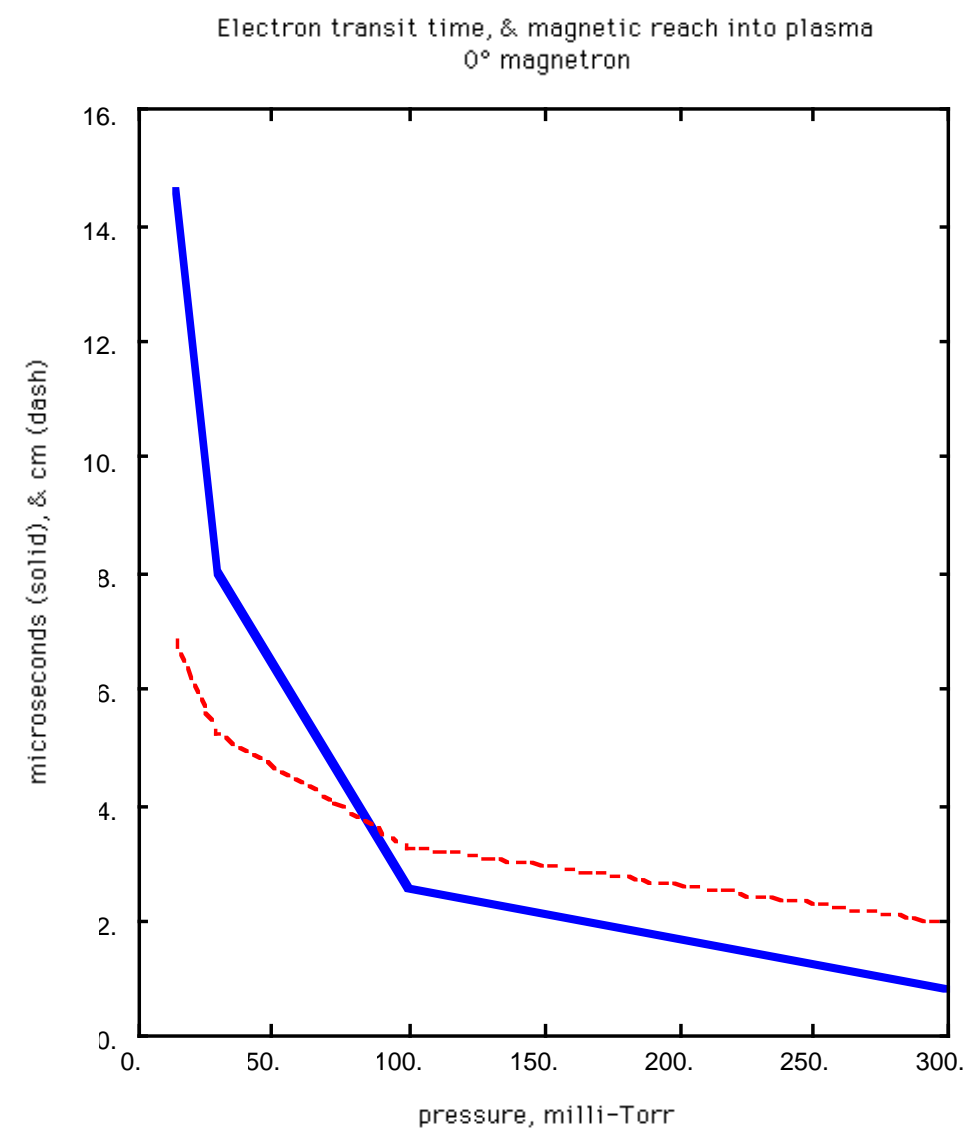

Figure 5: Electron fluid transit time $(\tau, \mu s)$, and extent of magnetron cathode fall $\left(y_{0}, \mathrm{~cm}\right)$

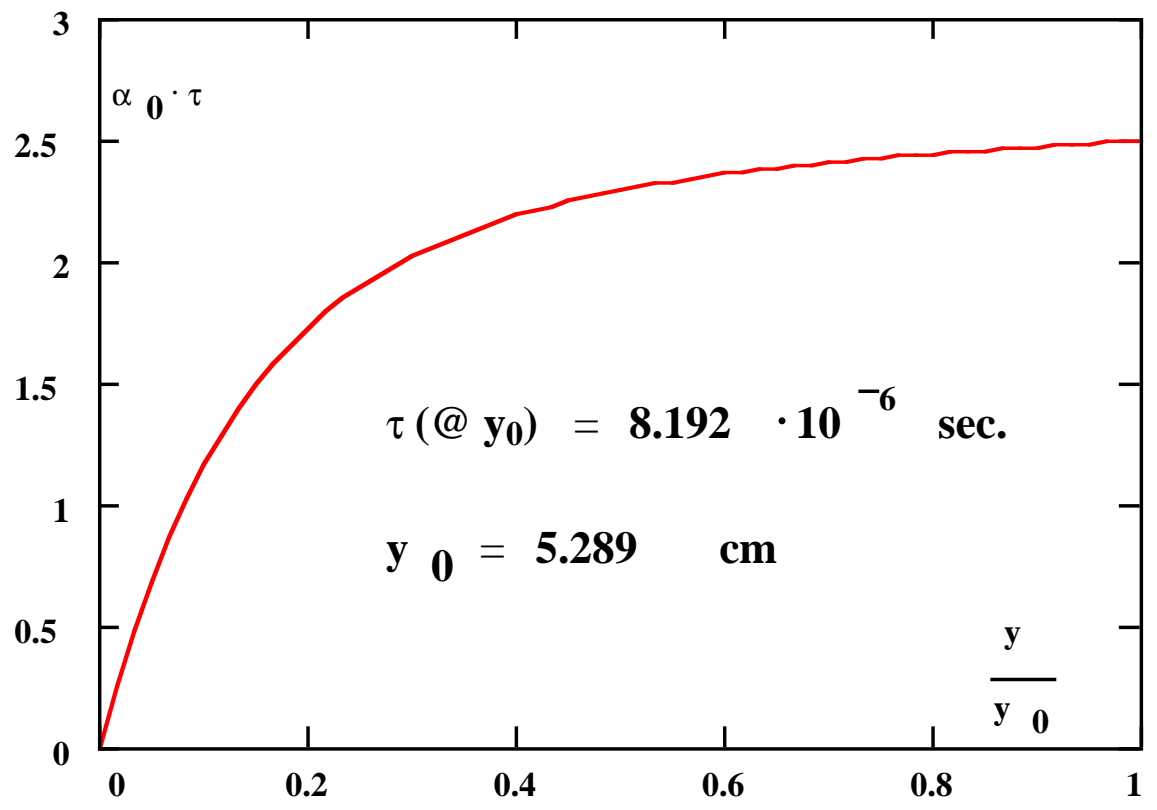

Figure 6: $\alpha_{0} \tau$ through magnetron cathode fall $\left(T_{e}=7 \mathrm{eV}\right)$, $\left(B_{\text {surface }}=520\right.$ gauss, $p=30$ milli-torr, $\quad V=200$ volts $)$ 
Figure 6 shows the profile of dimensionless product $\alpha_{0} \tau$ through the magnetized cathode fall in this $0^{\circ}$ example. This plot can be viewed as the average number of ionizations per transported electron charge at a given distance from the cathode surface. Estimates of helium glow discharge $\alpha_{0} \tau$ range between 1.5 and 3 . One estimate is the product $\left[\alpha_{0}\left(\varepsilon_{\mathrm{c}}=\mathrm{V}_{\mathrm{c}} \cdot \lambda_{\mathrm{e}} / \mathrm{d}_{\mathrm{c}}\right)\right] \times\left[\mathrm{d}_{\mathrm{c}}\left(\mathrm{V}_{\mathrm{c}}, \mathrm{p}\right)\right] /\left[\mathrm{v}_{\mathrm{e}}\left(\varepsilon_{\mathrm{c}}\right)\right]$, where $\mathrm{V}_{\mathrm{c}}$ is the cathode fall voltage, $\mathrm{d}_{\mathrm{c}}$ is the fall length (which depends on $\mathrm{V}_{\mathrm{c}}$, and pressure), $\lambda_{\mathrm{e}}$ is electron mean free path, $\varepsilon_{\mathrm{c}}$ is an electron energy, and $\mathrm{v}_{\mathrm{e}}$ is the electron velocity. $\mathrm{V}_{\mathrm{c}}, \mathrm{d}_{\mathrm{c}}$, and $\alpha_{0}(\varepsilon)$ are taken from data ${ }^{2,3}$.

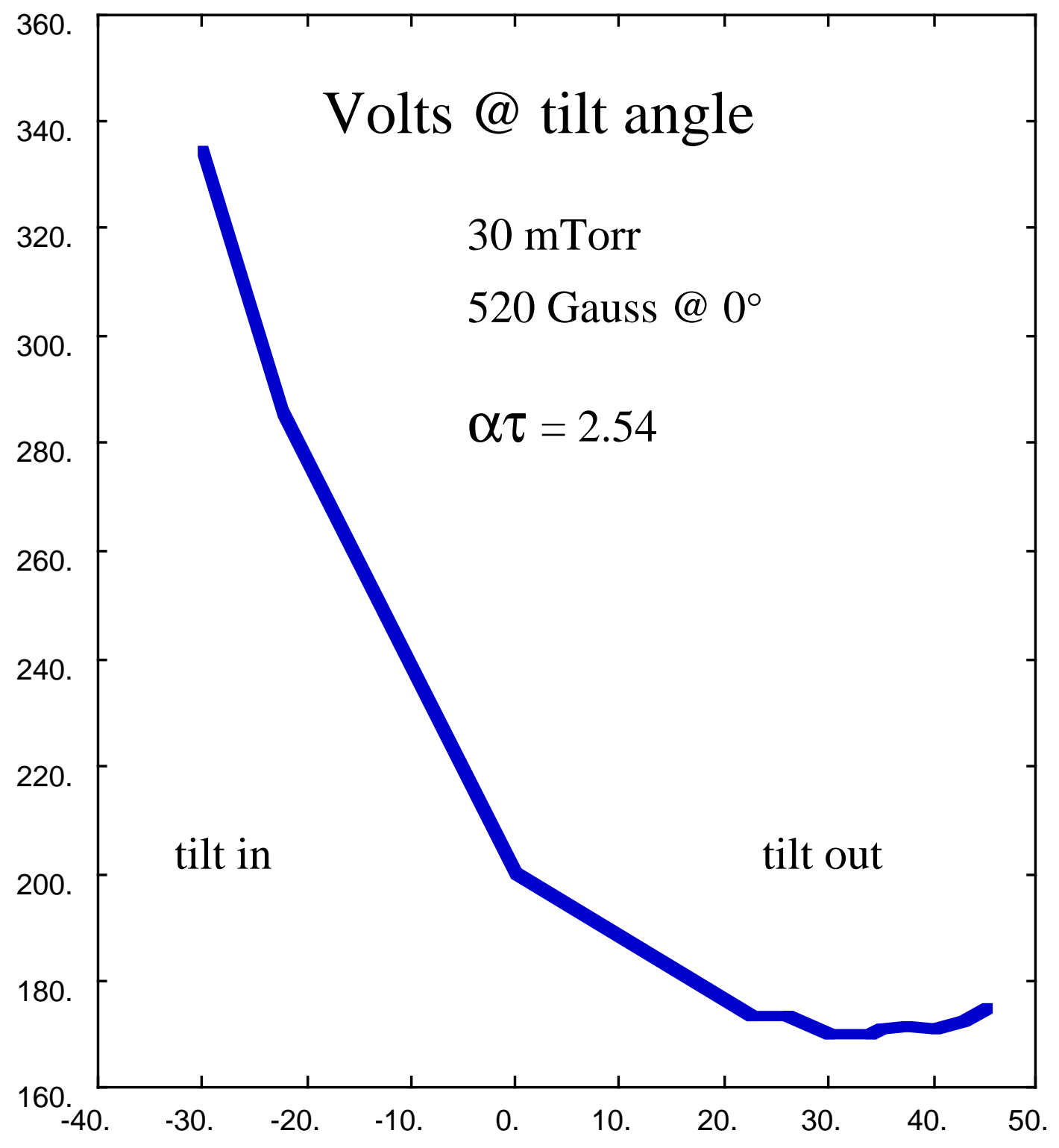

Figure 7: Model volts @ tilt angle in degrees

Experiments showed that magnetron halos had a preference for the sides of magnets, between their pole faces. When the magnets of 
the $0^{\circ}$ geometry were tilted away from the cathode normal, they tended to look more like a single magnet at $90^{\circ}$, and the voltage required to conduct a given current fell. The fin magnetron described earlier is essentially a $90^{\circ}$ arrangement where the "top" and "bottom" sides (between poles) of the magnet are utilized as either side of the fin. The fin magnetron cathode operated at 160 volts DC, with little variation between 15 and 300 milli-torr. This trend of voltage with magnet tilt is captured in model calculations where $\alpha_{0} \tau=2.54$, see

Figure 7.

By comparing experiment with theory it is found that the appropriate electron temperature to use in any simulation of a magnetron cathode fall in helium is that which gives $\alpha_{0} \tau \approx 2.5$. A glow discharge that conducts the same current will produce the same $\alpha_{0} \tau$, though at much higher voltage. On the basis of this criterion a wide variety of magnetron cathode geometries can be calculated and compared. The model now becomes a useful engineering tool.

\section{Example: PEPC $0^{\circ}$ Magnetron Cathode}

An example of the use of this model will be given by showing a variety of cross sectional views for an idealized $0^{\circ}$ PEPC magnetron cathode. In this example $\mathrm{p}=30$ milli-torr, $\Phi_{\infty}=280$ volts, $\mathrm{B}_{\mathrm{x}-\max }=$ 1560 gauss, $\mathrm{j}_{\infty}=1.2 \mathrm{~mA} / \mathrm{cm}^{2}, \mathrm{I}_{0}=5.18 \mathrm{~mA} / \mathrm{cm}$ (of track length), $\mathrm{T}_{\mathrm{e}}=$ $4.5 \mathrm{eV}$. A schematic of the magnetron is shown as Figure 8. The calculations span a section of the (XY) plane from the cathode surface to the edge of the cathode fall $\left(\mathrm{y}_{0}\right) 8.7 \mathrm{~cm}$ away ( $\mathrm{Y}$-axis in Figure 8), and twice as wide as the pole-to-pole spacing of the magnets, or 3.75 $\mathrm{cm}$ wide $\left(0\right.$ to $-X_{B}$, or 0 to $X_{B}$ in Figure 8$)$. Figure 9 shows the orientation of the illustrations in Figure $\mathbf{1 0}$ through Figure 16, which is from the cathode surface, centered on the track, and out towards the plasma. Figure $\mathbf{1 0}$ through Figure $\mathbf{1 6}$ are selfexplanatory and show the spatial distributions of all interesting physical quantities. They are appended to the end of this report. 


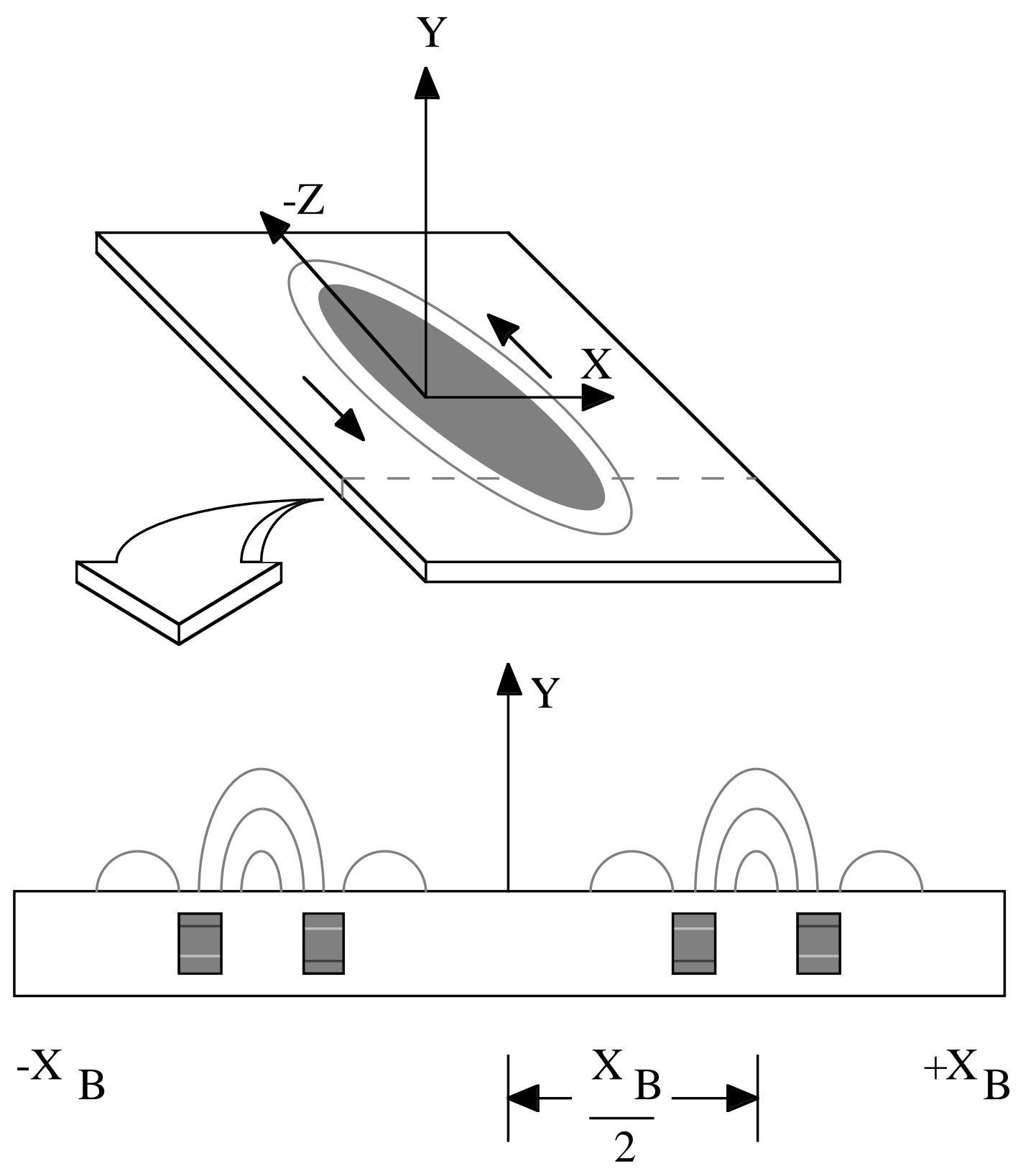

Figure 8: Schematic of idealized $0^{\circ}$ PEPC magnetron cathode 


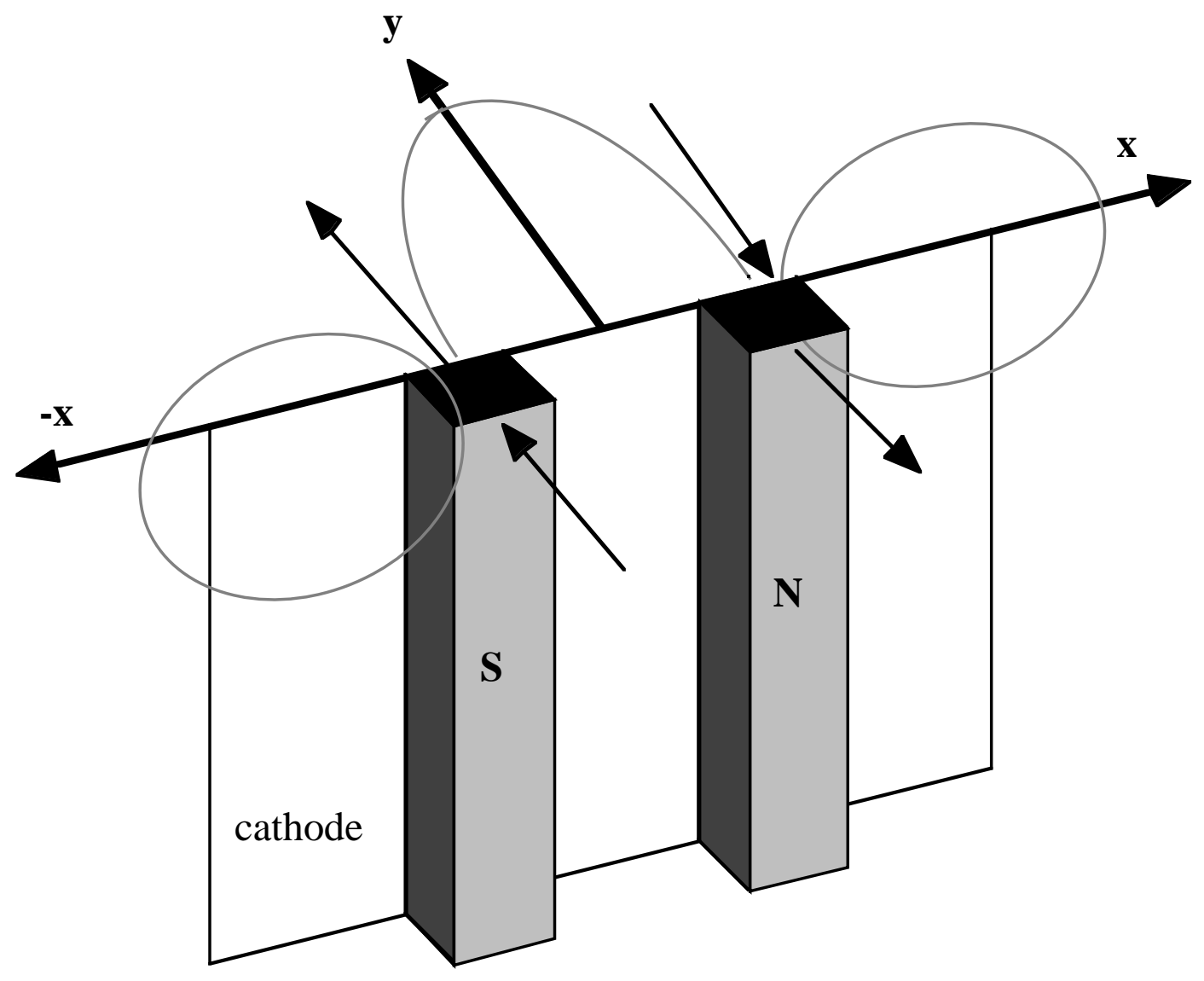

Figure 9: Orientation of PEPC example cross sectional views

\section{Applicability of the model}

The next point to be discussed is the issue of using a fluid model, with no charge imbalance and electrostatic sheaths, to model a low density, magnetized cathode fall. It is well known that fluid models capture the global aspects of energy flow even in situations of low electron-neutral collision frequency, especially if magnetism is present $t^{4,5}$. This model includes the collision frequencies $v_{\mathrm{eN}}$ and $v_{+} \mathrm{N}$ explicitly, and thus it includes terms in the momentum equations that are usually eliminated in simple fluids models where $1 / v_{\mathrm{eN}}$ and $1 / v_{+N}$ are taken as zero. This helps to extend the applicability to rarefied conditions. 
The present model has a logical inconsistency in that:

$$
\begin{aligned}
& \nabla \cdot \mathbf{E}=\frac{\rho_{\mathrm{c}}}{\varepsilon_{0}} \\
& \rho_{\mathrm{c}}=\mathrm{e}\left(\mathrm{n}_{+}-\mathrm{n}_{\mathrm{e}}\right) \\
& \rho_{\mathrm{c}}>0, \quad \mathrm{n}_{+} \approx \mathrm{n}_{\mathrm{e}} \quad \text { (quasi-neutrality) } \\
& \mathrm{E}_{\mathrm{z}}>0, \quad(2 \mathrm{D}, \text { no } \mathbf{E} \| \text { track) } \\
& \frac{\partial \mathrm{E}_{\mathrm{x}}}{\partial \mathrm{x}}+\frac{\partial \mathrm{E}_{\mathrm{y}}}{\partial \mathrm{y}}=0 \\
& \mathrm{E}_{\mathrm{x}}<<\mathrm{E}_{\mathrm{y}} \quad(\text { equipotentials } \| \text { cathode) } \\
& \text { yet: } \partial \mathrm{E}_{\mathrm{y} / \partial \mathrm{y} \neq 0}
\end{aligned}
$$

In the model $\mathrm{E}_{\mathrm{y}}(\mathrm{y})$ is defined by a balance between electron joule heating and ionization.

Let $\Delta \mathrm{n}$ represent the charge imbalance required in order to produce (or counteract) local $\mathrm{dE}_{\mathrm{y}} / \mathrm{dy}$. If $\Delta \mathrm{n} / \mathrm{n}<<1$, then quasineutrality is a good assumption. Figure 17 shows the results of calculating $\Delta \mathrm{n} / \mathrm{n}$ along the cathode fall at the midplane of the track, for the example described above. In regions of low density the model is less likely to apply, but then those regions are of little effect and interest in DC operation. The discrepancy with $\Delta \mathrm{n} / \mathrm{n}<<1$ is largest at the cathode surface and diminishes to insignificance with coordinate $y$. The local electric field is seen to be small in comparison to the electric field within a Debye length, except very close to the cathode. This indicates that throughout most of the cathode fall there is more than enough charge to produce the electric field without a significant departure from charge neutrality. Also, the assumption of a continuum plasma is reasonable because there are many Debye lengths within the length scale of the cathode fall.

Naturally, close to the cathode surface both the assumptions of a continuum and quasi-neutrality must break down, and a nonneutral particle model is required. The point here is that a fluid model is more likely to give a wider range of utility and detail for engineering purposes than any particle model. 

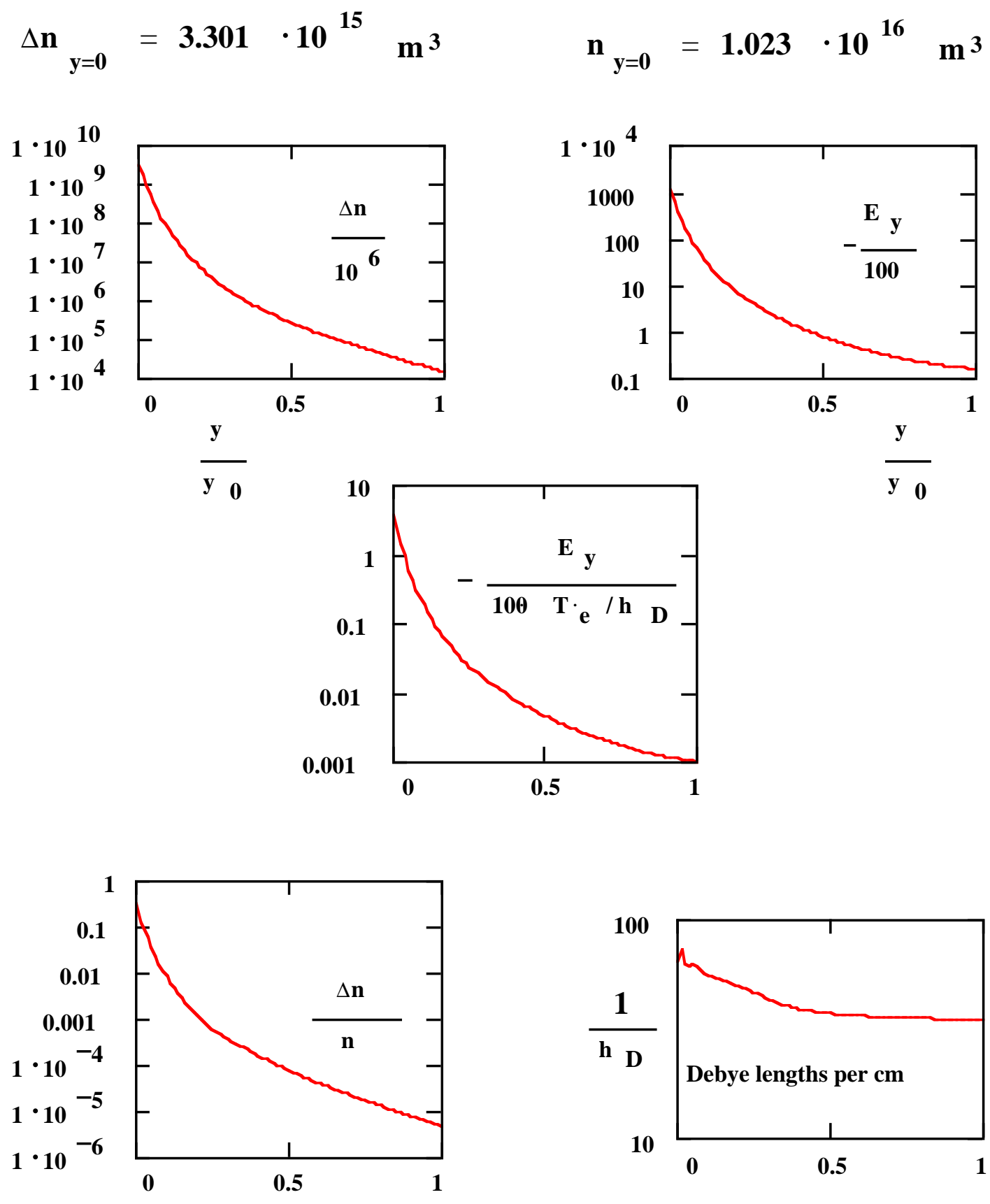

Figure 17: Charge imbalance profile along centerline of track. Plot scales: density difference in $\mathbf{c m}^{-3}$, electric field in $V / \mathbf{c m}$, inverse Debye length in $\mathrm{cm}^{-1}$. Ratios for charge imbalance density, and cathode/Debye fields. All plots along $\mathbf{y} / \mathbf{y}_{0}$.

Other comments

The electron fluid spirals out of the track until it merges into a bulk flow along the discharge axis. It can be seen in Figure 13 that $v_{y}$ 
increases with distance from the cathode while $\mathrm{v}_{\mathrm{z}}$ diminishes. This spiral could be seen by the luminosity pattern along the glass wall of the discharge experiment.

High field and current pulses applied to the DC magnetron cathode discharge will generate arcs along surfaces of $B_{x}=0$. Note the spikes in $\mathrm{v}_{\mathrm{y}}, \mathrm{j}_{\mathrm{ey}}$, and $\mathrm{jey}_{\mathrm{e}} \cdot \mathrm{E}_{\mathrm{y}}$ in Figures 13, 14 and 15 . Electrons in these regions, though relatively few in number during DC operation, are quite free to move, to quickly gain energy, and to initiate ionization avalanches that grow into sparks. Beware of the quasistatic approximation: that pulsed operation will look like a DC plasma with much larger density. Regions of $B_{x}=0$ can be thought of as low inductance zones, whereas those of tightly confined plasma are high inductance zones with respect to the global discharge circuit. If the pulse time scale is large compared to the magnetron cathode $\tau$, then the quasi-static approximation is reasonable. In the idealized PEPC example, $\tau=113 \mu \mathrm{s}$ at the midplane of the track, and $3 \mu \mathrm{s}$ above the pole faces.

\section{Conclusions}

Five conclusions have been reached:

1) $\alpha_{0} \tau$ is the parameter that determines $T_{e}$ in the cathode fall model, and for helium $\alpha_{0} \tau \approx 2.5$.

2) $\alpha_{0} \tau$ for a magnetron cathode fall is equivalent to $\alpha_{0} \tau$ for a glow discharge carrying the same current.

3) The model describes the overall plasma and energy flow in $2 \mathrm{D}$ and $\mathrm{DC}$, given the proper $\mathrm{T}_{\mathrm{e}}$.

4) Continuum plasma and quasi-neutrality are good approximations. Fluid models are useful for engineering.

5) Pulsing may channel the discharge current into an arc along the $\mathrm{B}_{\mathrm{x}}=0$ surface. Quasi-static behavior occurs when the pulse time scale is much larger than the parameter $\tau$.

\section{Acknowledgments}


I am grateful for the assistance of Gene Donohue and Cal Robb with the experiments, of Scott Fochs for his help in preparing presentations (e.g. Figure 2) and for many helpful discussions, and for the interest and challenges (do experiments!) presented by Mark Rhodes, the PEPC project leader. I am especially grateful to Chuck Boley for his comments on the energy equation. This work was performed under the auspices of the U.S. DOE by LLNL under contract no. W-7405-Eng-48.

\section{References}

1) M. Garcia, "A 2D Fluid Model of the DC Planar Magnetron Cathode," UCRL-ID-122494, 15 November 1995.

This report can be viewed online at: http://www.1lnl.gov/tid/lof/lof_home.html. Search for "garcia," and this report will be among those listed. The report can be viewed using the utility Adobe Acrobat Reader (freely available, for example from the LLNL library webpage).

2) J. D. Cobine, Gaseous Conductors, Dover Publications, Inc., New York, 1958

3 E. W. McDaniel, Collision Phenomena in Ionized Gases, John Wiley \& Sons, Inc., New York, 1964

4 T. G. Cowling, Magnetohydrodynamics, Adam Hilger Ltd, Bristol, UK, 1976. See chapter 6, "Rarefied Plasmas."

5) F. F. Chen, Introduction to Plasma Physics, Plenum Press, NY, 1974. See section 3.3.4, "Comparison with Ordinary Hydrodynamics." 


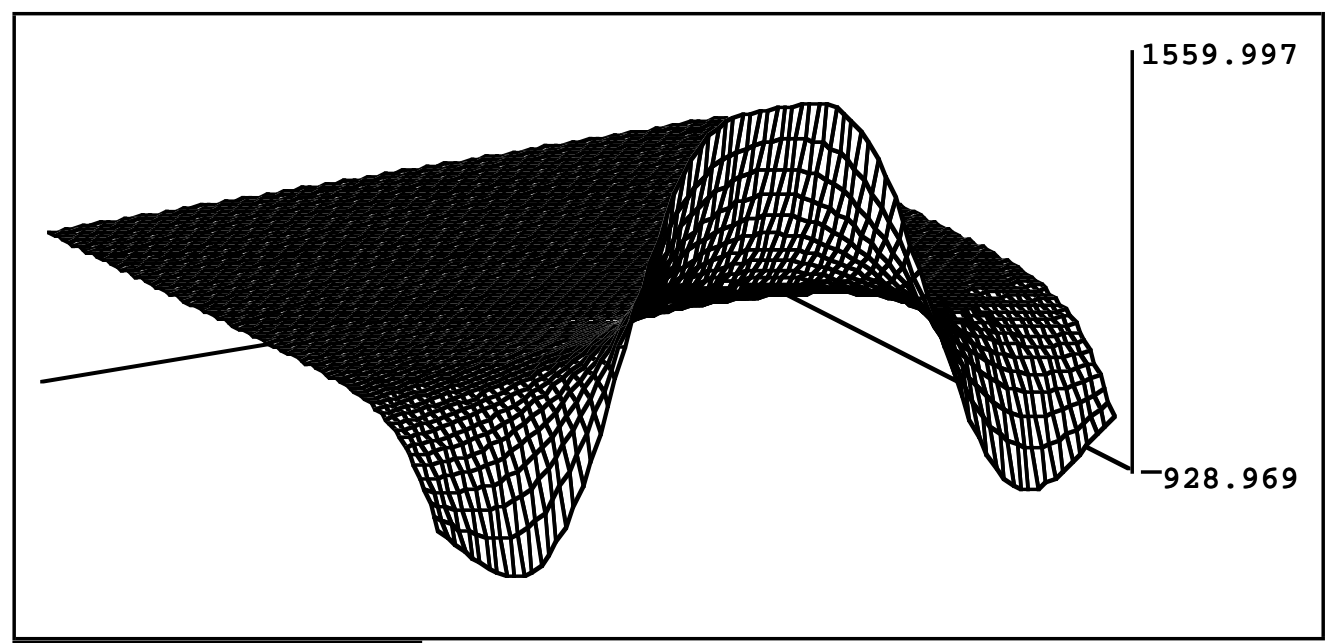

$\mathrm{B}_{\mathrm{x}}$, gauss

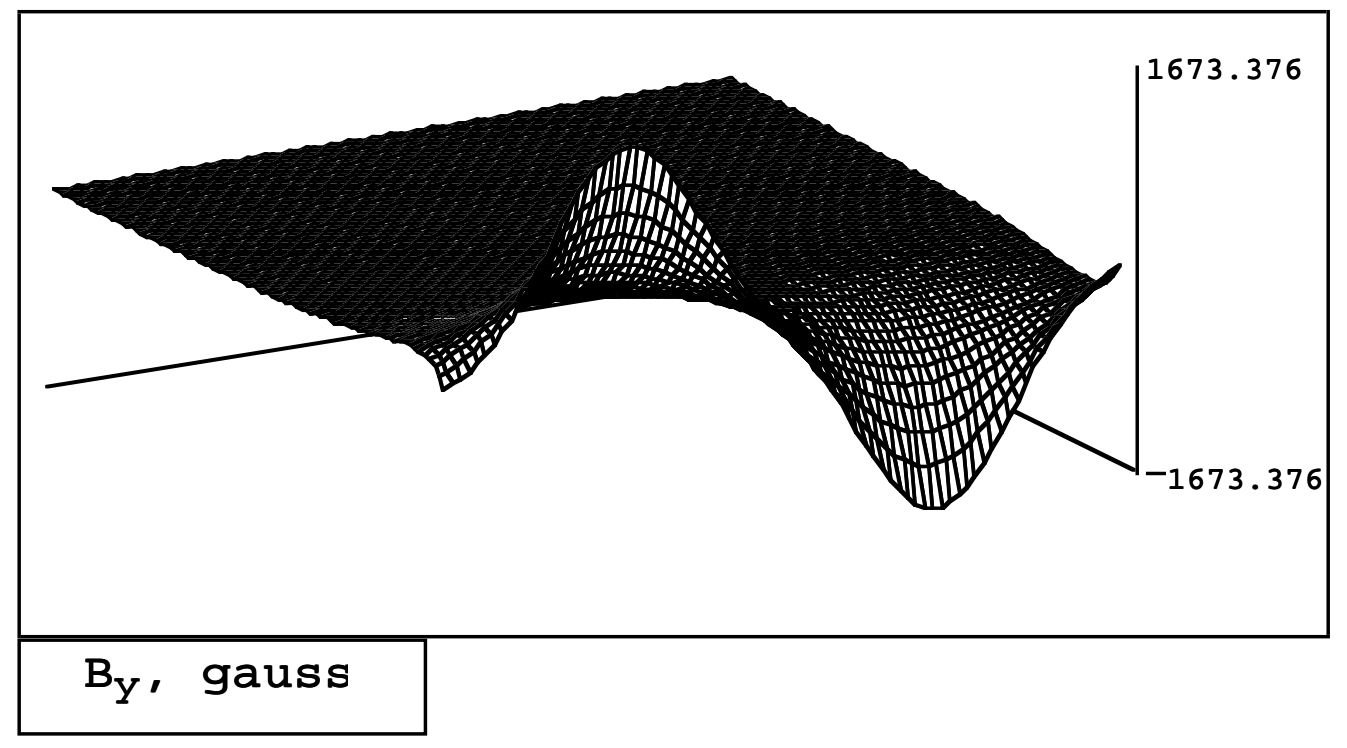

Figure 10: $B_{X}$ (transverse) and $B_{y}$ (perpendicular), gauss. Pole faces reside where $B_{y}$ is of large amplitude. 

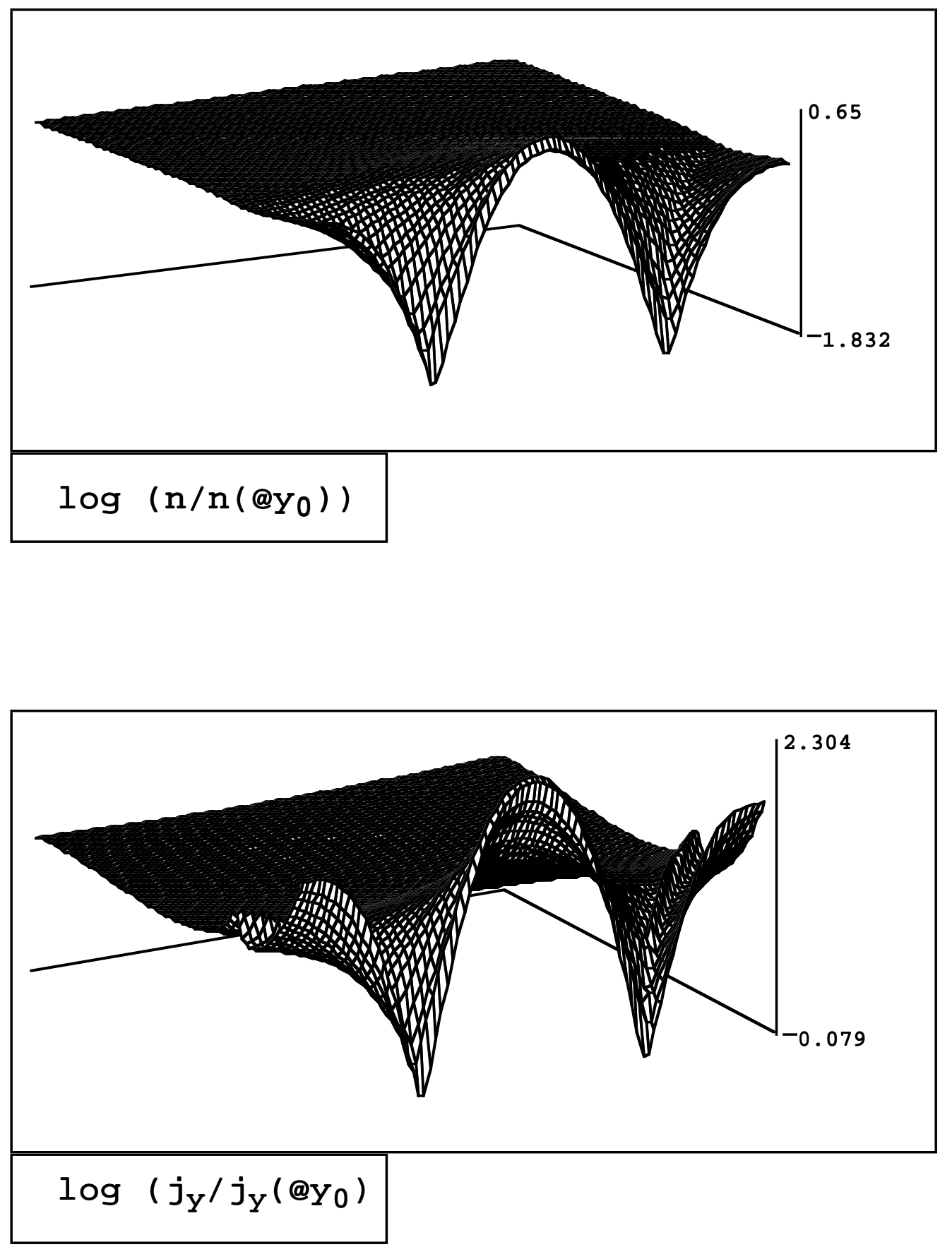

Figure 11: Relative logarithmic distributions:plasma \& perpendicular current density. Note minima over poles. 


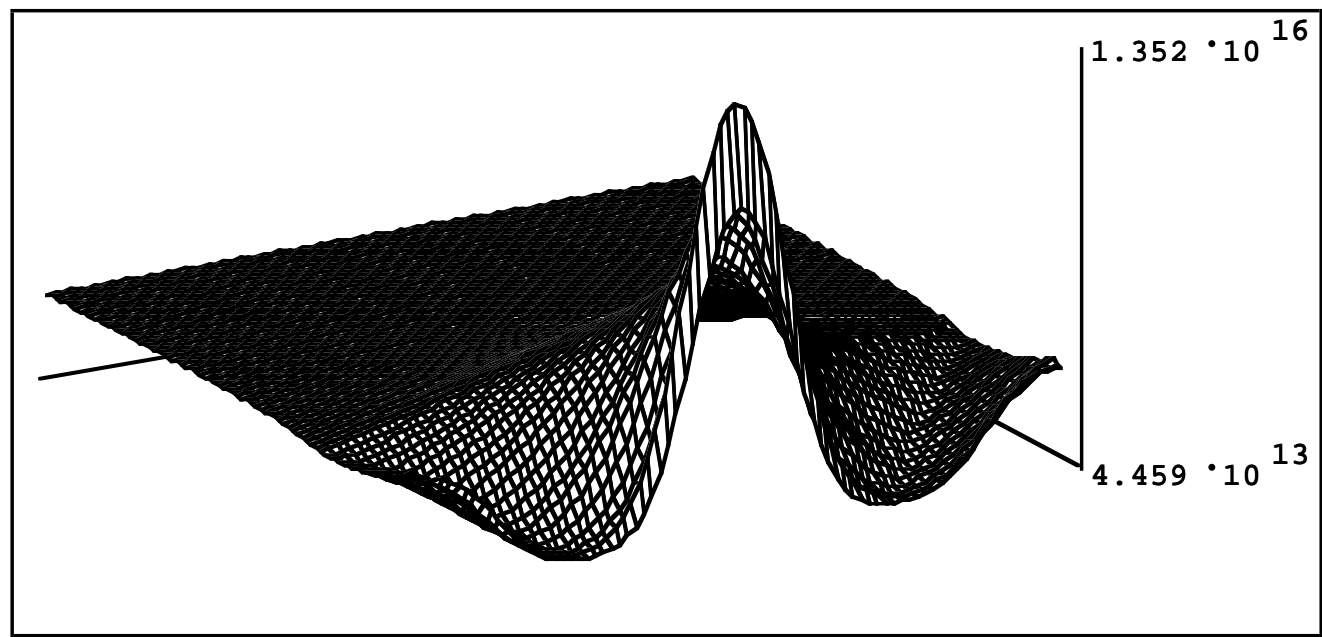

$\mathrm{n}, \quad \# / \mathrm{m}^{3}$

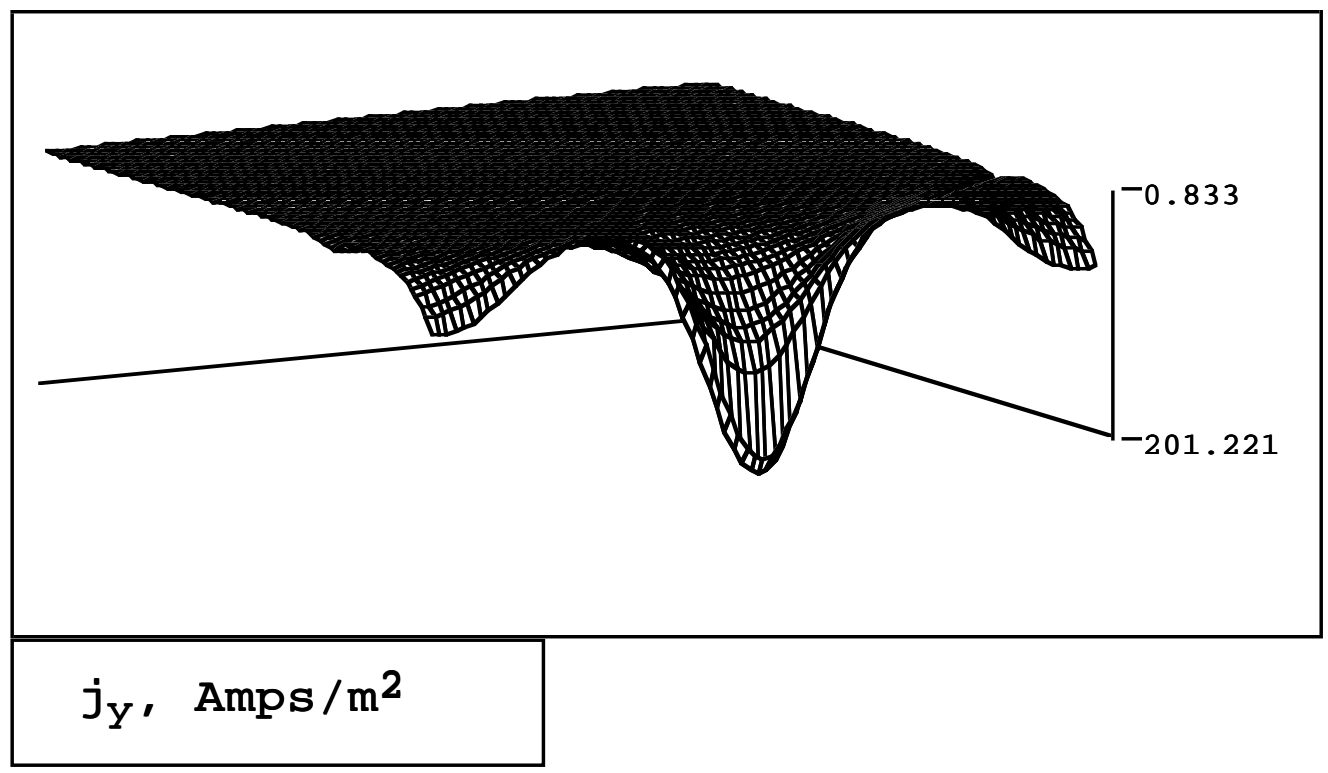

Figure 12: Distribution of plasma anderpendicular current density. Note x-edges: not all the circuit currenfuniseled between the magnets. 

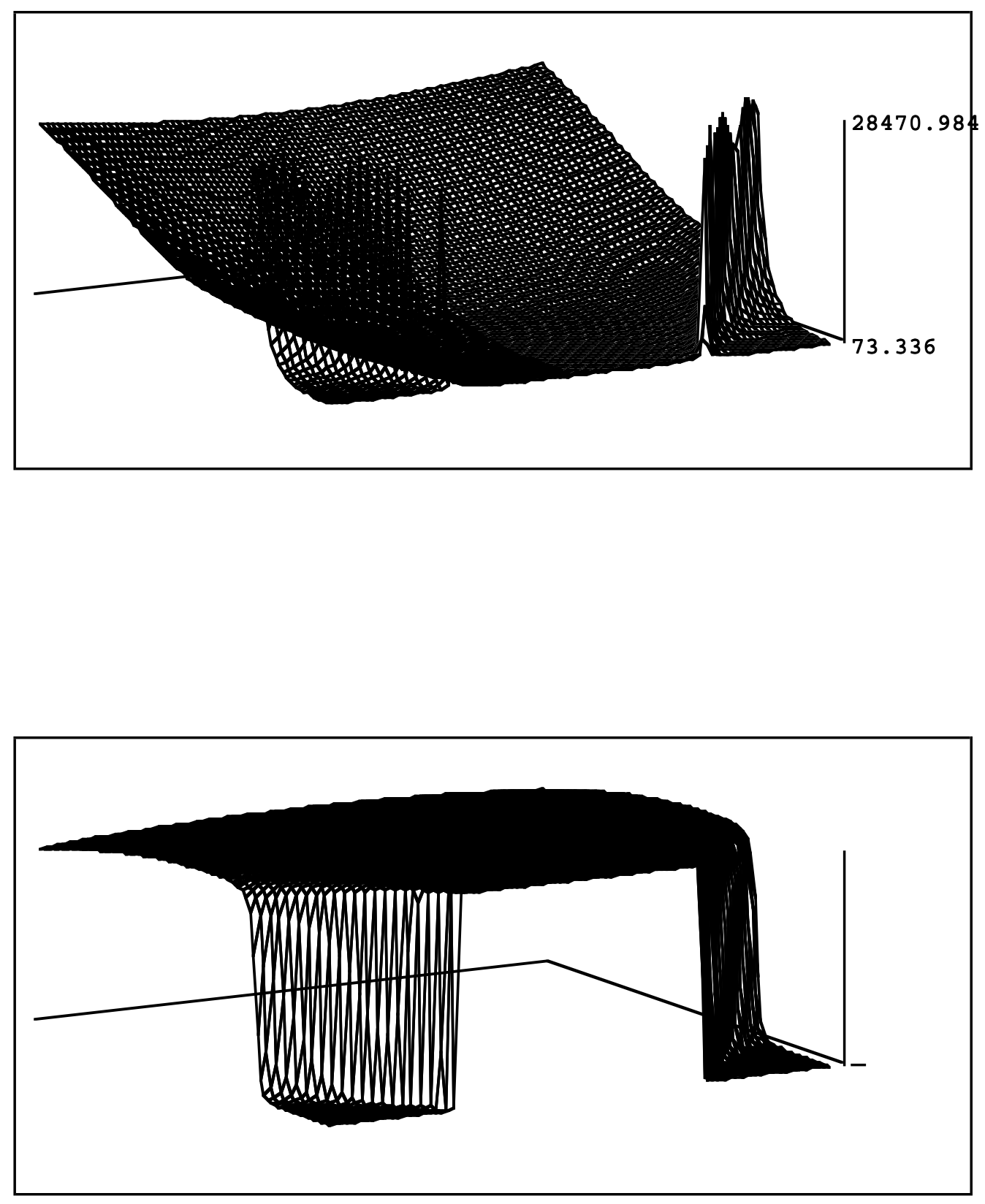

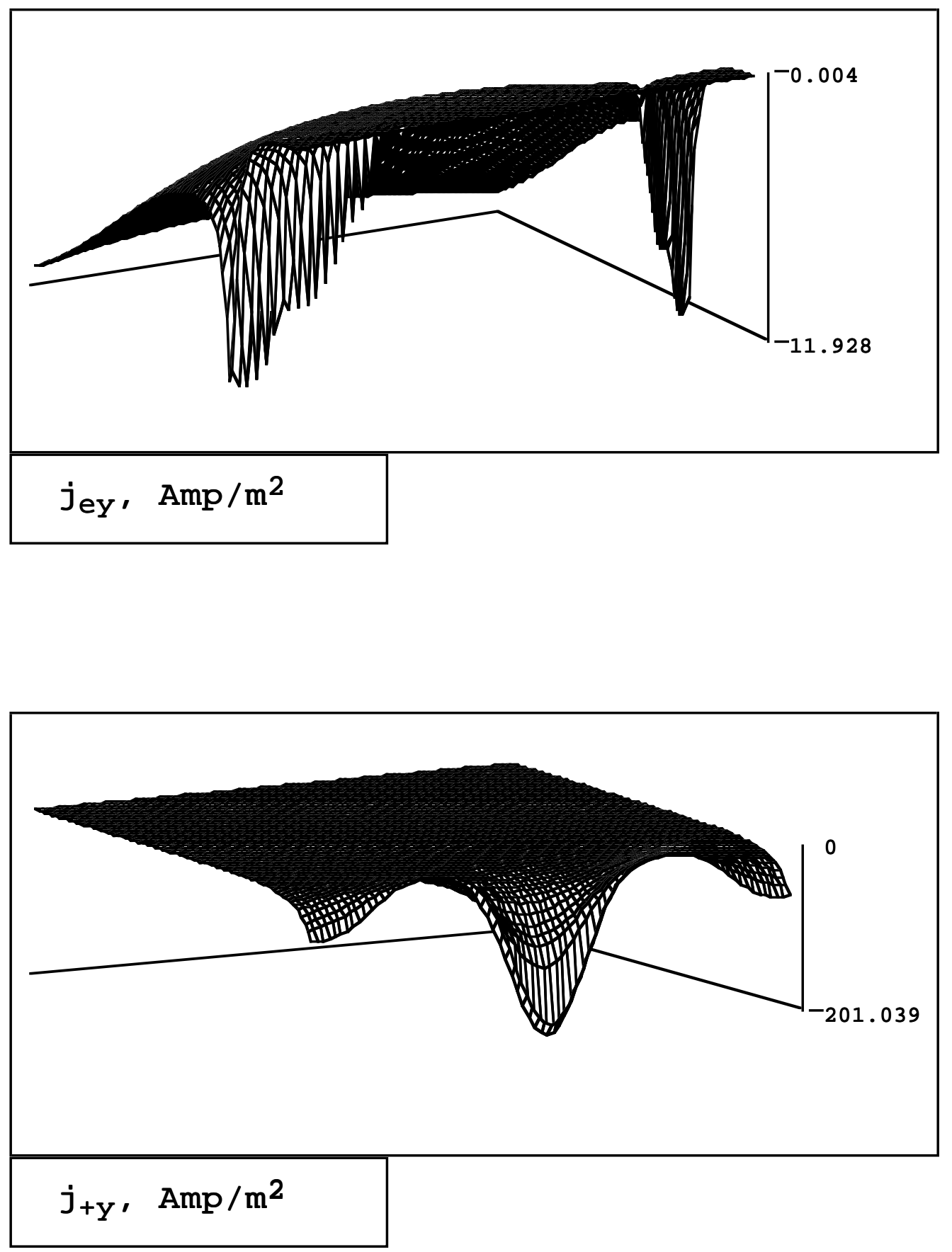

Figure 14: Electron and ion portions of perpendicular current density. Note transition from electron carriers to ion carriers of circuit current in cathode fall. Espeeter trench profile to look like $j_{+y}(x, y=0)$. 

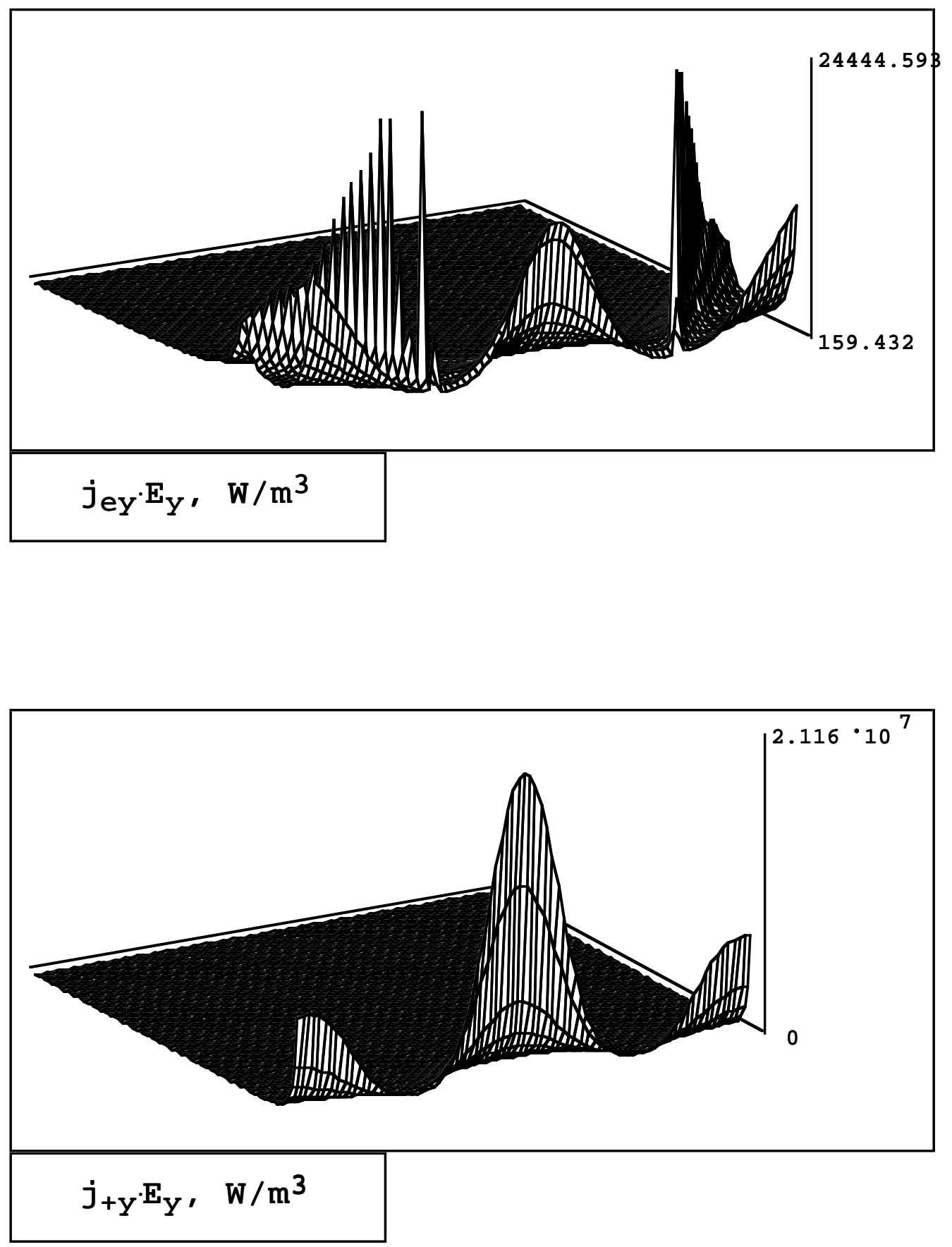

Figure 15: Electron and ion power densities. These show regions of ionization, and particleacceleration.Ion power at $y=0$ suggests profile of sputter trench. 


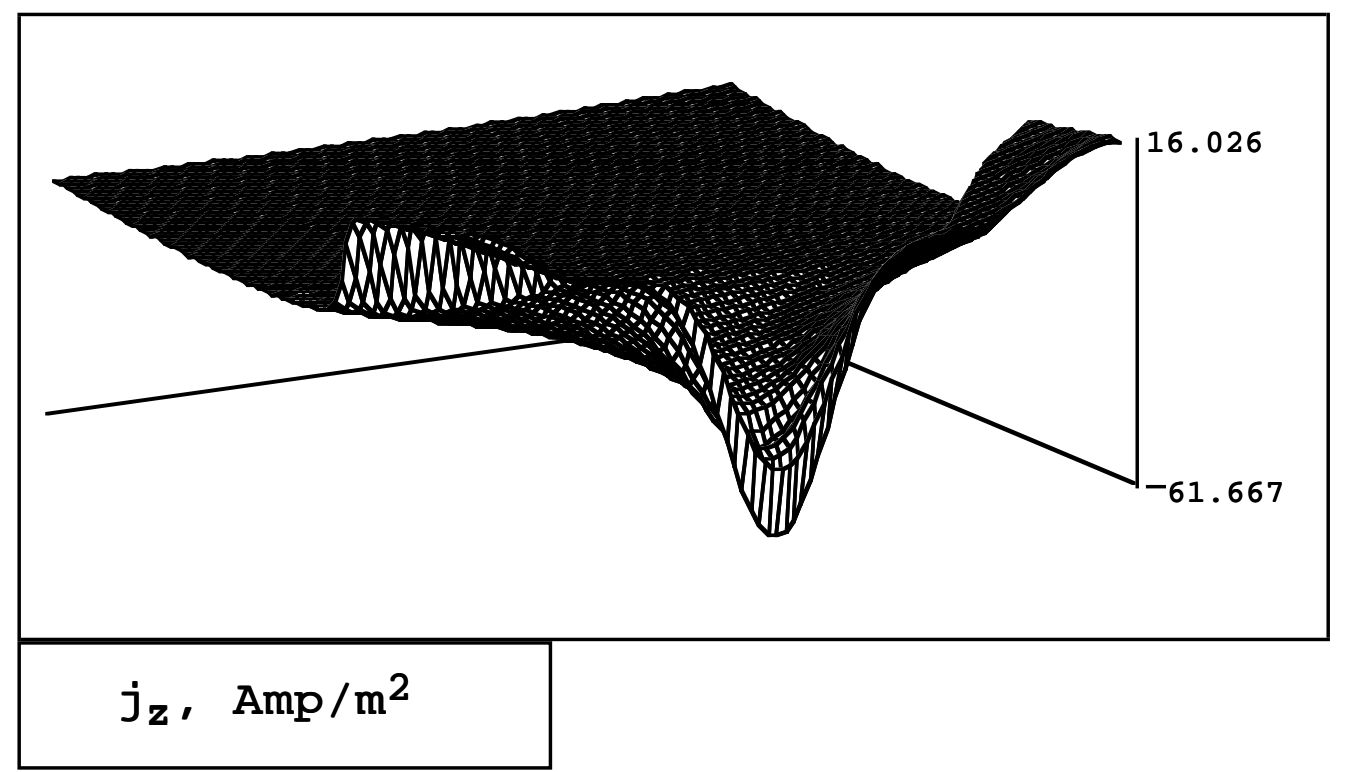

Figure 16: Magnetron current density. This is purely an electron drift parallel to the cathode surface along the closed track. Note the opposite directions drfiftinside the track, and outside along the magnet shoulders. 



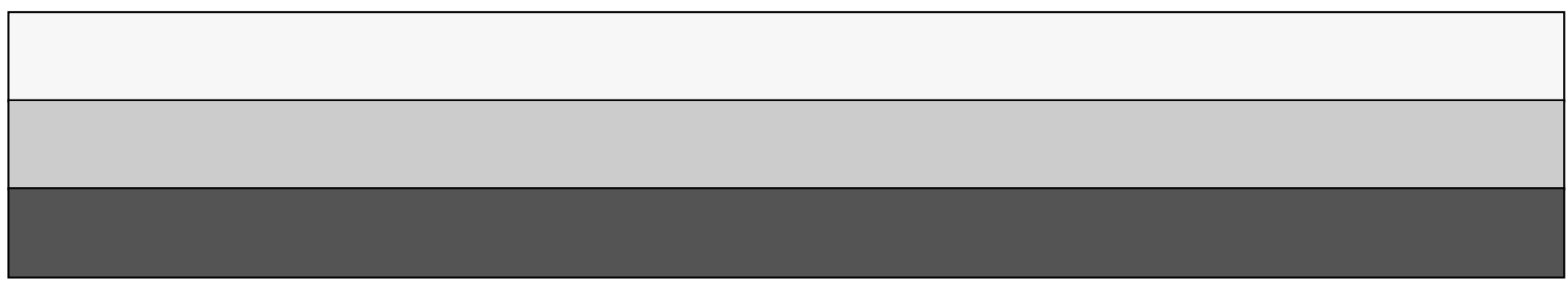

